\title{
The NICE COPD Guidelines 2004-what are the messages for primary care?
}

\author{
David Bellamy*,1
}

James Fisher Medical Centre, 4 Tolpuddle Gardens, Muscliffe, Bournemouth, Hants BH9 3LQ UK

COPD is an important and common disease which causes persistent and increasing symptoms to patients, impairment of quality of life and leads to 30,000 deaths per year in the UK. It is a considerably burden to the National Health Service, particularly in the winter months when exacerbations occur most commonly and result in $13 \%$ of all acute medical admissions.

The first UK COPD Guidelines were produced by the British Thoracic Society in 1997. Since then there have been many new devetopments in treatment and management and the need for updated guidelines, drawn up on more critically evidenced based criteria, has become more pressing.

The new guidelines were commissioned by the National Institute for Clinical Excellence (NICE) and were researched and written by the National Collaborative Centre on Chronic Conditions to the highest evidence based standards. They have the full support of the British Thoracic Society and have been published in full format with all evidence tables and references in Thorax [1]. Other shorter and patient orientated versions of the guideline are available on the NICE website [2]. The BTS COPD Consortium has produced a short summary document to be distributed to all primary care and some secondary care practitioners and a set of teaching slides on Powerpoint which can be downloaded from the BTS website [3].

The new guideline emphasises that COPD not only affects the lungs and breathing, but can produce other effects such as muscle wasting and fa-

\footnotetext{
*Tel.: +44-1202-522622; fax: +44-1202-548580.

E-mail address: david.bellamy@virgin.net (D. Bellamy).

${ }^{1} \mathrm{GP}$ member of NICE Guideline Committee.
}

tigue, weight loss, pulmonary hypertension and cor pulmonale, anxiety and depression. Patients with COPD should therefore have access to a wide range of skills delivered from a multidisciplinary team. The patient is central in providing good disease education and involving them in decision making on therapy and management.

\section{Making a diagnosis}

Making the correct diagnosis of COPD and differentiating it from asthma is one of the seven key themes of the new guideline.

There is no single diagnostic test for COPD. Making a diagnosis relies on clinical judgement based on a combination of history, age, physical examination and confirmation of the presence of airflow obstruction using spirometry.

The diagnosis of COPD depends crucially on thinking of it in the first place as a possible cause of breathlessness or cough in any smoker or ex-smoker over the age of 35 years [4]. The key symptoms remain:

- exertional breathlessness;

- chronic cough;

- regular sputum production;

- frequent winter bronchitis;

- wheeze.

Spirometry remains the gold standard for demonstrating airflow obstruction to confirm the diagnosis. It should be performed at the time of diagnosis; opportunistically, not more often than once per year; or to reconsider the diagnosis if patients show an exceptionally good 
response to treatment. It should also be repeated if there is a more rapid than expected decline in symptoms.

In concert with most international guidelines, airflow obstruction is defined as a reduction in FEV1 of $<80 \%$ of predicted value, plus a reduced FEV1/ FVC ratio below $70 \%$.

\section{Reversibility testing}

One of the major changes in the new guideline is the advice on the role of spirometric reversibility testing to bronchodilators and a trial of oral steroids. While spirometry remains essential for confirming the diagnosis of airflow obstruction, reversibility testing is no longer routinely recommended for all patients. The correct diagnosis of COPD, and its differentiation from asthma, can usually be made on clinical grounds and where necessary, by careful assessment of response to treatment.

The reasoning behind this new stance is based on clinical studies and observations. It is now recognised that there are many difficulties with the old approach and that routine spirometric reversibility testing may be unhelpful or misleading because:

- repeated FEV1 measurements can show small spontaneous fluctuations;

- the results of reversibility tests performed on the same patient on different occasions can be inconsistent and not reproducible $[5,6]$;

- over-reliance on a single reyersibility test may be misleading unless the change in FEV1 is very large (e.g. greater than $400 \mathrm{ml}$ );

- the definition of what constitutes the magnitude of a significant change is purely arbitrary (and has varied between 10 and $20 \%$ in different settings);

- response to long-term therapy is not predicted by acute reversibility testing.

This view on routine reversibility testing is shared by both the American and European Respiratory Societies and is likely to be adopted by GOLD in the near future.

There has been much discussion about this recommendation with regard to a seeming conflict with the necessity to perform reversibility testing on all patients to fulfil the requirements of the new GP contract in the UK. Opinions have been expressed that removing the need to perform reversibility testing in primary care would result in too many patients with asthma being missed. It is also encourages good practice to make primary care practitioners think and test objectively to make the correct diagnosis.

However, while reversibility testing in all patients might be the pinnacle of excellence, in real life and practically, how many practices will have the time or adequately trained staff to perform these tests to the appropriate technical level? Surveys show spirometry is poorly performed in primary care and unless patients are properly briefed about with-holding bronchodilators for sufficient time before doing reversibility testing, the results would be meaningless.

The GP contract conflict is likely to be resolved as now that NICE has published the Guideline, discussions are taking place with the Department of Health to modify the GP contract. In the meantime, having performed diagnostic spirometry, patients could be given a trial of short acting bronchodilator for 3-4 weeks and reassessed both symptomatically and by lung function.

NICE is keen to emphasise that there is still a place for reversibility testing and in those patients where there remains uncertainty about the diagnosis, the following may be of benefit in identifying asthma.

- FEV1 and FEV1/FVC ratio return to normal.

- A very large (>400 $\mathrm{ml}$ ) response in FEV1 to either bronchodilator on prednisolone $30 \mathrm{mg}$ daily for 2 weeks.

SerialPEF readings showing significant $(20 \%$ or greater)-diurnalor day to day variability.

If patients report a dramatic improvement in symptoms in response to inhaled therapy either acutely or over a more prolonged period of time, the diagnosis of asthma should be considered. Patients with remaining diagnostic uncertainty should be referred for specialist advice and more detailed investigations.

Clinical features differentiating COPD and asthma

\begin{tabular}{lll}
\hline & COPD & Asthma \\
\hline $\begin{array}{c}\text { Smoker or } \\
\text { ex-smoker }\end{array}$ & Nearly all & Possibly \\
$\begin{array}{c}\text { Symptoms under } \\
\text { age } 35\end{array}$ & Rare & Often \\
$\begin{array}{c}\text { Chronic productive } \\
\text { cough }\end{array}$ & Common & Uncommon \\
$\begin{array}{c}\text { Breathlessness } \\
\text { Pight waking, } \\
\text { breathlessness or } \\
\text { wheeze }\end{array}$ & $\begin{array}{l}\text { Persistent and Variable } \\
\text { progresive }\end{array}$ & \\
$\begin{array}{c}\text { Significant diurnal } \\
\text { or day to day } \\
\text { variability of } \\
\text { symptoms }\end{array}$ & Uncommon & Common \\
\hline
\end{tabular}




\section{Classification and assessment of disease severity}

Traditionally, the severity of COPD has largely been equated with the FEV1 \% predicted value. We now better understand that COPD is a systemic disease which may affect parts of the body other than the lungs and accordingly disability, affecting exercise, the activities of daily living, quality of life, and mood all have a significant effect on the patient. Mild airflow obstruction can be associated with significant disability. A true assessment of severity should therefore not only include spirometry but other measures such as:

- A measure of breathlessness (MRC dyspnoea scale).

- Enquiry of how COPD is affecting general daily living.

- Frequency of exacerbations.

- Weight loss (BMI).

- Oxygen saturation with a pulse oximeter (which becomes a strongly recommended piece of equipment for primary care).

- The presence of cor pulmonale.

The NICE Guideline has produced new levels of gradation of airflow obstruction according to FEV1\% predicted which are shown in the table. These have been selected:

- To harmonise with new levels in most international guidelines.

- To reflect the threshold for undertaking various assessments and starting new treatments.

Severity of airflow obstruction according to FEV1 \% predicted

\begin{tabular}{ll}
\hline Severity & FEV1 \\
\hline $\begin{array}{l}\text { Mild airflow obstruction } \\
\begin{array}{l}\text { Moderate airflow } \\
\text { obstruction }\end{array}\end{array}$ & 30-80\% predicted \\
$\begin{array}{l}\text { Severe airflow obstruction } \\
\text { Sevedicted }\end{array}$ & Below 30\% predicted
\end{tabular}

\section{New recommendations on drug treatment}

Since the initial BTS Guidelines, there have been a considerable number of published studies with Grade A or B evidence levels which have clarified the role of some of the newer agents now available for symptomatic relief, improvement of quality of life and prevention of exacerbations.
Smoking cessation remains a key part of the management as it is the only measure to affect the rate of decline of lung function.

\section{Inhaled bronchodilators}

Short acting bronchodilators, both beta-agonists and anticholinergics, remain as the initial treatment for the relief of breathlessness and exercise limitation.

The effectiveness of such therapy should not be assessed by lung function alone but should include a variety of other measures such as improvement in symptoms, activities of daily living and exercise capacity.

Patients who remain symptomatic should have their inhaled treatment intensified to include long-acting bronchodilators (both beta-agonists and anticholinergics) or combined therapy with a short acting beta-agonist and short acting anticholinergic.

Long-acting bronchodilators should be added in patients who remain symptomatic despite short acting bronchodilators or who have two or more exăcerbations per year, lbecause they show added benefits over short acting therapy. These include a greater effect on symptom control, a significant improvement in quality of life scores, and the ability to reduce the frequency of acute exacerbations.

The choice of drug should be determined with reference to efficacy, side effects, patient preference and cost effectiveness.

\section{Inhaled corticosteroids}

NICE has concurred with recent evidence [7] that steroid reversibility tests do not predict response to inhaled steroid therapy and should not be used to identify which patients should be prescribed inhaled steroids.

Inhaled corticosteroids should be prescribed for patients with a FEV $1 \leq 50 \%$ predicted who are having two or more exacerbations in the last year. The aim of treatment is to reduce exacerbations and slow the rate of decline in health status and not to slow the rate of decline in lung function.

Combining therapies from different drug classes can increase clinical benefit.

\section{Mucolytic therapy}

Mucolytic therapy may see a resurgence of interest and should be considered in patients with chronic 


\section{FLOW CHART FOR TREATMENT OF BREATHLESSNESS}

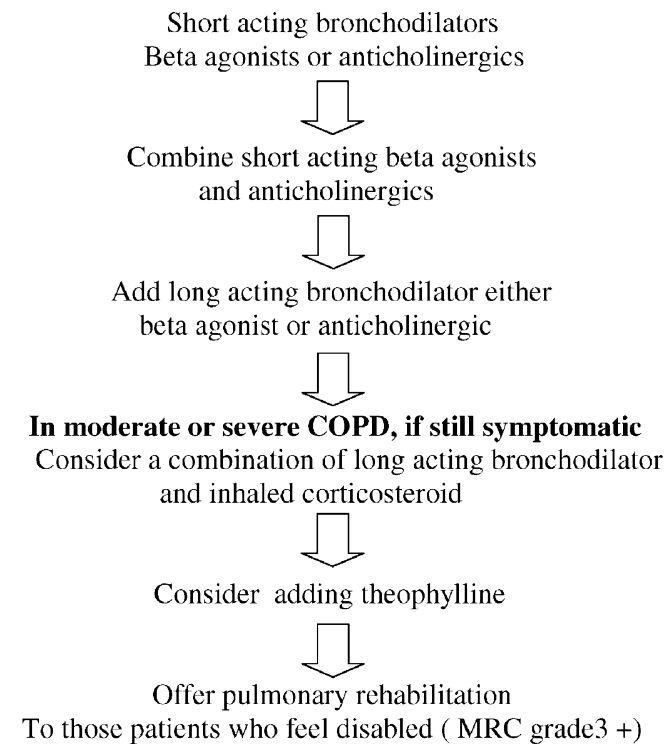

productive cough. The aim of treatment is to reduce frequency of cough and sputum production. However, a meta-analysis [8] of such agents used for more than 2 months has shown evidence of a reduction in exacerbations by $29 \%$ compared with placebo. More research is needed but this may prove a useful group of agents in preventing exacerbations.

Currently the only agent that can be prescribed in the UK is carbocysteine (mucodyne).

\section{Pulmonary rehabilitation}

The new guidelines stress the value to patients of rehabilitation which should be made available to all appropriate patients - those who consider themselves functionally disabled by COPD (usually MRC Grade 3 and above).

It should be accessible in terms of access, location and availability.

\section{Treatment of acute exacerbations}

Exacerbations cause marked worsening of symptoms and quality of life for the patient and can take as long as 2 months for symptoms to return to baseline. Once they start to occur they tend to continue. Most patients with severe COPD have $2-3$ exacerbations per year. Exacerbations requiring hospital admission are often a bad prognostic factor.

The NICE Guideline has emphasised the need to attempt to reduce the frequency and severity of exacerbations as well as providing treatment for attacks.
An exacerbation is defined as a sustained worsening of the patient's symptoms from their usual stable state which is beyond normal day to day variations, and is acute in onset. Common symptoms are worsening breathlessness, cough, increased sputum production and change in sputum colour. The change in symptoms often necessitates a change in medication.

Pulse oximetry is encouraged in primary care to aid the assessment of clinical severity of an exacerbation.

Primary care management of an exacerbation consists of:

- increase in bronchodilators - consider giving via a nebuliser;

- antibiotics if sputum is purulent;

- Prednisolone $30 \mathrm{mg}$ daily for 7-14 days.

Patients should be reviewed afterwards and management optimised as appropriate.

\section{Prevention of exacerbations}

Aiming to reduce exacerbations both in frequency and severity may have a major impact on reducing patient's suffering and decreasing the burden on acute admissions.

The following may help to reduce the frequency of exacerbations:

- Vaccinations: influenza and pneumococcal.

- Long-acting bronchodilators.

- Inhaled corticosteroids.

- Combined long acting beta-agonists and inhaled corticosteroids.

- Mucolytic agents.

- Self management action plan.

- Pulmonary rehabilitation.

\section{Self management action plans}

Self management plans have proved very valuable in asthma but their use in COPD is less clear with little research to promote their use. A hospital based controlled study by Bourbeau et al. [9] has shown approximately $40 \%$ reduction in hospital admissions and emergency room visits with a self management plan but a recent Cochrane review [10] was less positive.

The main aim is to provide patients at risk of exacerbations with self management advice in terms of an action plan that encourages them to respond promptly to the symptoms of an exacerbation. 
- Start oral steroids if breathlessness increases and interferes with activities of daily living.

- Start antibiotics if sputum becomes purulent.

- Adjust bronchodilator therapy to control symptoms.

Suitable patents should be prescribed a supply of antibiotics and prednisolone to keep at home for use as part of a self-management strategy. Early and appropriate use of treatment may help to reduce the duration and severity of exacerbations and perhaps prevent a hospital admission. They should be advised to contact a healthcare professional if they do not improve.

\section{Palliative care}

Patients with end stage COPD have little access to the sort of palliative care provided for terminal cancers. NICE stresses that COPD sufferers, their family and carers should have access to the full range of services offered by multidisciplinary palliative care teams, including admission to hospices.

\section{Conclusions}

The NICE Guidelines are a welcome addition to the best clinical diagnosis and management of COPD. Many guidelines end on a shelf unread or worse in the rubbish bin. The dissemination process by the BTS Consortium will ensure that a brief, easily read summary of the Guideline is seen in every surgery in the UK and for those outside the UK the materials, together with a teaching/lecture slide set are available free on the BTS website.

\section{References}

[1] National clinical guideline on management of chronic obstructive pulmonary disease in adults in primary and secondary care. Chronic Obstructive Pulmonary Disease. National Collaborating Centre for Chronic Conditions. Thorax 200459(Suppl 1):1-232.

[2] http://www. nice.org.uk/cat.asp?c=104441.

[3] http://www.brit-thoracic.org.uk.

[4] van Schayck CP, Loozen JM, Wagena E, et al. Detecting patients at high risk of developing chronic obstructive pulmonary disease in general practice: cross sectional case finding study. BMJ 2002;317:1433.

[5] Nisar M, Earis JE, Pearson MG, et al. Acute bronchodilator trials in chronic obstructive pulmonary disease. Am Rev Resp Dis 1992;146:555-9.

[6] Calverley PMA, Burge PS, Spencer S, et al. Bronchodilator reversibility testing in chronic obstructive pulmonary disease. Thorax 2003;58:659-64.

[7] Burge PS, Calverley PMA, Jones PW, et al. Prednisolone response in patients with chronic obstructive pulmonary disease: results from the ISOLDE study. Thorax 2003;58:6548.

[8] Poole P, Black PN. Oral mucolytic drugs for exacerbations of chronic pulmonary disease: a systematic review. BMJ 2001;322:1271-4.

[9] Bourbeau J, Jutien M, Maltais F, et al. Reduction of hospital utilization in patients with chronic obstructive pulmonary disease-a disease specific self management intervention. Arch Int Med 2003;163:585-91.

[10] Monninkhof EM, van der Valk P, van der Palen J, et al. Self management education for patients with chronic obstructive pulmonary disease: a systematic review. Thorax 2003;58:394-8.

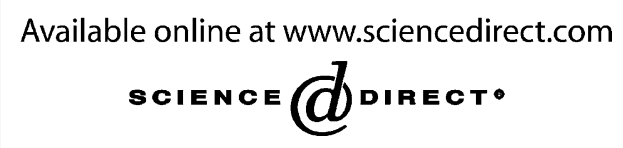

Available online at http://www.thepcrj.com 